\title{
ANÁLISE HISTÓRICA DO USO DA TERRA EM ANTROPOGEOMORFOLOGIA: ALGUNS EXEMPLOS PAULISTAS
}

\author{
Estêvão Botura Stefanuto, Felipe Augusto Scudeller Zanatta, Cenira Maria Lupinacci
}

Universidade Estadual Paulista Júlio de Mesquita Filho

\begin{abstract}
Resumo
Com a intensa utilização das terras pela sociedade, verificam-se alterações cada dia mais significativas sobre o modelado do relevo. Essa situação criou a necessidade de mudanças também no âmbito do conhecimento geomorfológico, dando origem à denominada antropogeomorfologia, que busca confrontar historicamente o uso dos terrenos e as mudanças na morfologia do relevo. Assim, este artigo objetiva demonstrar a importância desse tipo de análise para identificar as alterações nas dinâmicas de superfície. Para isso apresenta-se a revisão dos princípios clássicos da Teoria Geral dos Sistemas; de noções de incerteza, complexidade e não linearidade; e a análise de estudos de caso em áreas urbanas e rurais. Conclui-se que os dados históricos permitem levantar hipóteses sobre a possível dinâmica desses ambientes alterados, contribuindo para reduzir o grau de incerteza.
\end{abstract}

Palavras-chave: complexidade, não linearidade, geomorfologia antropogênica.

\begin{abstract}
The intense use of the land by the society makes possible to verify more and more significant changes about the modeling of the relief. This situation created the need for changes also in the scope of geomorphological knowledge, giving rise to the so-called antropogeomorphology, which seeks to confront historically land use and changes in the relief morphology. Therefore, this paper aims to demonstrate the importance of this type of analysis to identify changes in surface dynamics. We present the revision of the classical principles of the General Theory of Systems; of notions of uncertainty, complexity and non-linearity; and the analysis of case studies in urban and rural areas. We conclude that the historical data allow to raise hypotheses about the possible dynamics of these altered environments, contributing to reduce the degree of uncertainty.
\end{abstract}

Key words: complexity, non-linearity, anthropogenic geomorphology.

$\mathrm{N}$ os últimos séculos, a interação entre as organizações humanas e a natureza tem ocorrido de forma predatória, não compreendendo os seres humanos como parte da natureza, mas sim como uma força de domínio da mesma. Esse descompasso entre a sociedade e a natureza se potencializou a partir do século XVII com o alvorecer da ciência moderna (CHAUI, 1994) e início do século XVIII com a Revolução Industrial (HOBSBAWM, 1981), processos que transformaram a relação da humanidade com os sistemas naturais. Na Geomorfologia, estudiosos como Tricart (1956) já enfocavam a ação antrópica em meados do século passado. De forma semelhante, Brown (1971) também já apontava as ações diretas do homem sobre as formas do relevo e as indiretas, através de efeitos provocados sem intencionalidade. No entanto, Nir (1983) destacou que nem toda intervenção humana é direcionada contra os processos naturais, uma vez que tais 
ações podem seguir a mesma direção do fenômeno, de modo a alterar seu ritmo, sendo isso o suficiente para abalar o estado de equilíbrio dinâmico.

Mediante a intensa alteração da natureza e consequentemente do modelado do relevo, Zalasiewicz et al. (2016) afirmaram que parte das mudanças no sistema terrestre ocorreram através da deposição de materiais de origem antrópica, compreendendo sedimentos artificiais, compostos por lama e areia misturados com materiais sintéticos. Para os autores, o ser humano já produziu, mesmo em um curto período de tempo, materiais com características distintas das que compõe o Holoceno, fomentando assim o surgimento de uma nova era geológica, intitulada de Antropoceno.

Com terminologia distinta, mas reforçando a teoria apresentada por Zalasiewicz et al. (2016), para Peloggia (1998), a partir dos avanços técnicos das sociedades humanas surgiram inúmeras formas de urbanização e de produção agrícola, que atualmente atingem um estágio de modificação da paisagem que ultrapassa os limites dos processos naturais, chegando a suscitar a designação de um novo período geológico: o Quinário ou Tecnógeno. A partir das proposições apresentadas, constata-se que a inserção de nova era ou período na tabela cronoestratigráfica está em debate, sendo, contudo, consenso seu início a partir de 1950.

Em meio a tais discussões, verifica-se um direcionamento das pesquisas em geomorfologia para compreender do tempo presente, o qual integra, segundo Suertegaray e Nunes (2001), o tempo diagnóstico, que se utiliza de intervenções e atuações imediatas sobre o relevo, permitindo uma sobreposição da escala de tempo histórica sobre a geológica, além de maior desenvolvimento de análises pautadas em processos morfodinâmicos.

Nessa perspectiva de compreensão das dinâmicas naturais sob a interferência antrópica, Nir (1983) propôs um novo campo temático de pesquisa denominado de antropogeomorfologia, o qual utiliza a abordagem sistêmica e ferramentas clássicas da geomorfologia para avaliar o efeito das distintas formas de interferências antrópicas nas dinâmicas naturais dos diversos ambientes existentes no planeta. Para Haff (2008), esse novo campo temático, que o autor chama de New Geomorphology, trabalha com a imprevisibilidade da ação humana como cerne das ações modificadoras do relevo.

Segundo Goudie (1986), a antropogeomorfologia subdivide-se em duas principais áreas de investigação: a primeira direcionada aos impactos da atividade humana nos solos, analisando as mudanças das propriedades físicas e químicas dos mesmos; e a segunda visando compreender as alterações sobre as formas de relevo. Para o autor, os processos antropogenéticos podem ocorrer de forma direta ou indireta. Os diretos decorrem de mudanças na estrutura, que podem ser incisivas (compactação ou desfragmentarão do solo) ou graduais (terraços ou aração). Enquanto as ações indiretas, ocorrem como processos de aceleração da erosão e sedimentação, potencializados principalmente pelas atividades agrícolas, desmatamento, urbanização, em áreas de mineração, de ocupação de setores cársticos ou de falhamento e interferências em tremores de terra, como, por exemplo, com a construção de reservatórios hídricos em um plano de falha.

Rodrigues (2010) destaca que na análise antropogeomorfológica o elemento histórico ganha significativa relevância, sendo que as atividades humanas, em sua lógica espaço-temporal, mudam de acordo com o contexto social e os aprimoramentos técnicos. Em estudos de caso, a autora enfatiza a necessidade de reconstituição histórica do relevo da área de estudada no momento de desenvolvimento de uma pesquisa, através de uma retrospectiva do acúmulo histórico 
de intervenções antrópicas sobre o setor de análise. Através dessa retrospectiva, a comparação entre a morfologia primeira e as conseguintes permite levantar hipóteses quanto a dinâmica do ambiente estudado sobre interferência humana.

Ao considerar as questões supramencionadas, objetiva-se neste artigo discutir a importância da análise de dados históricos de uso da terra para a antropogeomorfologia a partir de alguns estudos de caso sobre o território paulista, desenvolvidos no Laboratório de Geomorfologia (LAGEO) do Instituto de Geociências e Ciências Exatas (IGCE), da Universidade Estadual Paulista (UNESP), campus de Rio Claro. Para isso, entretanto, será necessário discutir alguns dos princípios clássicos da Teoria Geral dos Sistemas aplicados à geomorfologia (HOWARD, 1973; CHRISTOFOLETTI, 1979; CHORLEY; KENNEDY, 1971; CHORLEY, 1971), bem como de estudos mais recentes, que buscam elaborar um campo teórico sobre o efeito da ação humana nos sistemas geomorfológicos (PHILIPPS, 1992; MURRAY et al., 2009).

\section{A questão metodológica}

A fim de discutir a complexidade agregada aos sistemas terrestres a partir da atuação antrópica e da análise retrospectiva para compreender as respostas sistêmicas, apresenta-se nessa seção alguns princípios da Teoria Geral dos Sistemas. Por conseguinte, discute-se o processo de transformação das análises geomorfológicas, do entendimento tradicional do relevo como um sistema processo-resposta, para o emprego da noção de sistemas complexos, regidos pela não linearidade dos fenômenos e pela incerteza.

Convém enfatizar que existem outras orientações teórico-metodológicas que visam o entendimento da complexidade na Geomorfologia, baseadas em Morin (2006) principalmente. Contudo, para este trabalho busca-se a linha de entendimento estabelecida por Nir (1983) e Rodrigues (2005) que defendem a Teoria Geral dos Sistemas como o caminho a ser seguido. Isso se deve ao fato desses autores terem um caminho técnico claramente estabelecido, baseado na cartografia geomorfológica e do uso da terra, para o entendimento da interação da ação humanarelevo.

Um sistema, conforme Christofoletti (1971), constitui-se de um conjunto de elementos que estabelecem relações entre si e seus atributos, sendo, para Howard (1973), um modelo geral para fenômenos naturais. Segundo Christofoletti (1979), os sistemas devem conter: elementos ou unidades; relações (compreendendo que os elementos de um sistema são dependentes um do outro); atributos (características de um sistema); entrada (input - aquilo que é recebido pelo sistema); e saída (output - aquilo que sai do sistema).

De acordo com a função de um sistema, Chorley e Kennedy (1971) classificam os sistemas em dois tipos:

1. Sistemas Isolados: não fazem troca, não recebem e não sofrem perda de matéria e energia com o ambiente circundante.

2. Sistemas não-isolados: realizam permuta de matéria e energia com outros sistemas do universo. Os sistemas não-isolados estão subdivididos em:

a) Sistemas fechados: quando há troca de energia (recebimento e perda), mas não de matéria. 
b) Sistemas abertos: quando há troca de matéria e energia, tanto input como output.

Dentre as principais características de um sistema aberto, destaca-se a busca pelo equilíbrio dinâmico que, de acordo com Christofoletti (1971, p. 55), constitui-se no "[...] estado de distribuição de energia no qual há ajustamento das variáveis internas às condições externas de energia", sendo o ajustamento responsável pela evolução das formas de relevo. Chorley (1971) afirmou que na prática, o equilíbrio dinâmico raramente é caracterizado por um equilíbrio de fato, sendo que, o que se evidencia, é a tendência a atingi-lo. Isso se deve às alterações de energia que ocorrem durante o funcionamento de um sistema aberto.

Conforme Christofoletti (1979), a análise dos sistemas deve considerar também o critério estrutural. Chorley e Kennedy (1971) diferenciam onze tipos de sistemas relacionados à complexidade estrutural. Desses onze, quatro reforçam a análise geomorfológica:

1) Sistemas Morfológicos: relacionados à forma dos elementos (seu aspecto visível, sua configuração) e suas propriedades físicas. Christofoletti $(1979$, p. 37) afirma que a forma é uma "[...] expressão espacial de um fenômeno [...]". As propriedades dos sistemas morfológicos abertos e fechados, "[...] podem ser consideradas como respostas ou ajustamentos ao fluxo de energia ou matéria através do sistema em sequência aos quais estão ligados" (CHRISTOFOLETTI, 1979, p.15).

2) Sistemas em Sequência (ou cascata): formados por subsistemas relacionados entre si, que funcionam em cadeia. Nos subsistemas, a saída (output) de matéria e energia de um subsistema indica a entrada (input) de matéria e energia no subsistema vizinho. Em sistemas em sequência, é importante a análise de relações entre entrada e saída. Ao analisar esse tipo de sistema é necessário reconhecer os reguladores dos subsistemas, já que os reguladores apresentam funções decisórias.

3) Sistemas de Processos-Respostas: formados pela junção dos sistemas morfológicos e sistemas em sequência. "Os sistemas em sequência indicam o processo, enquanto o morfológico representa a forma, a resposta a determinado estímulo" (CHRISTOFOLETTI, 1979, p. 17). As alterações neste sistema provocam mudanças nas formas dos elementos. Alterações nos sistemas morfológicos despertam modificações nos processos, alterando os inputs. Nos sistemas de processos-respostas, há uma busca pelo estado de equilíbrio (dado pela configuração assumida pelas formas) e produção do mecanismo de retroalimentação.

4) Sistemas Controlados: sofrem intervenção humana no fluxo de matéria e energia nos sistemas em sequência (processos) e na modificação do sistema morfológico (formas). O ser humano, nessa perspectiva tradicional, atua sobre os sistemas de processos-respostas.

Recentemente, Vicente e Perez Filho (2003), afirmam que a Teoria Geral dos Sistemas se constitui em uma possibilidade de análise da complexidade da natureza, uma vez que supera os mosaicos da ciência clássica, entendendo os sistemas terrestres de forma integrada.

Atualmente, a perspectiva dos sistemas complexos propõe uma releitura da Teoria Geral dos Sistemas, não constituindo em proposta divergente, mas sim uma tentativa de compreender as respostas dos sistemas terrestres frente a incerteza e não linearidade produzida pela atuação antrópica. 
A ideia de sistemas complexos não é nova, esses já eram discutidos ainda no século XIX a partir de consideração de Ratzel (1880, apud Carvalho, 1999), na qual o autor classifica a Terra como um único complexo. Posteriormente, Cholley (1964) sugere a combinação dos complexos, buscando compreender as inter-relações entre os elementos da natureza. Reclus (1985) apontou que a organização do espaço é composta por vários componentes e que através das interrelações da natureza e da sociedade forma-se um sistema complexo. Para Christofoletti (1999) os sistemas complexos possuem diversidade de elementos, encadeamentos, interações e fluxos que possibilitam a emissão de respostas não lineares por parte do sistema.

Para Philipps (1992), o caráter não linear é definido em função das descontinuidades que marcam a evolução dos sistemas, as quais são referidas em outras áreas de conhecimento como bifurcações. Tais descontinuidades (ou bifurcações), na geomorfologia, para Philipps (1992, p. 223), são provocadas por esforços que ultrapassam os limiares (thresholds), situação que dá origem a outro sistema. A presença de tais limiares e as dificuldades em reconhecê-los levou o autor a afirmar que esses implicam na não previsibilidade, o que gera uma aparente aleatoriedade que condiciona o caráter complexo de alguns sistemas. Sobre a aleatoriedade, Philipps (1992, p. 223) afirmou que, "[...] se alguém pudesse, de alguma forma, reunir dados suficientes ou conhecimento suficientemente detalhado, a aparente aleatoriedade poderia ser resolvida em componentes deterministas". Contudo, considera tal situação impossível diante das especificidades do objeto de estudo e, portanto, o reconhecimento da complexidade necessário para o desenvolvimento da geomorfologia.

Destaca-se que a dificuldade em se reconhecer os limiares, que quando ultrapassados, geram mudanças irreversíveis nos sistemas, deve-se tanto a dinâmica da natureza quanto, nos dias atuais, a ação humana sobre os sistemas de relevo. Murray et al. (2009), detalham essa questão ao afirmarem que os sistemas naturais buscam a auto-organização, e que essa pode sofrer interferências de sistemas de forçamento, sejam esses de origem natural ou antrópica. A partir da atuação dos sistemas de forçamento, um sistema poderá apresentar respostas não lineares, dificultando assim a capacidade de previsibilidade no que se refere as suas respostas, gerando incertezas. Murray et al. (2009) discorrem sobre a origem dos sistemas de forçamento, demonstrando que os mesmos podem ser provenientes de ações antrópicas, exemplificadas como grandes áreas agrícolas, setores de mineração e aglomerados urbanos; e/ou forçantes naturais, exemplificadas pelas glaciações.

Desta forma, propostas como os sistemas em sequência e os sistemas de processosrespostas, que pressupõem uma alteração morfológica previsível diante da entrada ou saída de matéria e/ou energia, passam a não atender as necessidades da ciência geomorfológica atual. Diante da intensa interferência antrópica, os sistemas terrestres emitem respostas de difícil compreensão a partir dos princípios teóricos clássicos.

Para se identificar o comportamento linear ou não linear dos sistemas são necessários parâmetros. Os parâmetros são propiciados a partir da analise comparativa ao longo do tempo. Dessa forma, os estudos que visam avaliar a ação antrópica sobre o relevo necessitam considerar as mudanças a partir do tempo histórico, considerando que essa é a temporalidade envolvida na ação do agente desencadeante das alterações. Conclui-se assim que a análise retrospectiva e histórica proporciona avanços científicos e tecnológicos, pois permite reconhecer se um determinado fenômeno é novo ou recorrente. 
A fim de ilustrar a aplicação da perspectiva da análise retrospectiva e histórica na antropogeomorfologia, serão discutidos estudos que utilizaram da cartografia geomorfológica e de uso da terra em distintos períodos de tempo, em ambientes geomorfológicos e antrópicos também diferenciados do estado de São Paulo. Assim, selecionaram-se os trabalhos de Silveira (2013), no município de Piracicaba, e de Fagundes e Lupinacci (2017), no município de Rio Claro, os quais enfatizaram ambientes urbanos; e de Stefanuto e Lupinacci (2017), no município de Analândia, e Zanatta, Cunha e Boin (2015) e Zanatta, Lupinacci e Boin (2017), no município de Marabá Paulista, que estudaram ambientes rurais.

\section{Resultados da análise histórica na Antropogeomorfologia}

Serão apresentados inicialmente dois estudos desenvolvidos em duas cidades de porte médio, Rio Claro (SP) e Piracicaba (SP), as quais representam o processo típico de ocupação e de expansão urbana do interior do estado de São Paulo.

Fagundes e Lupinacci (2017) visando compreender as interferências antrópicas sobre o relevo provocadas pelo processo de urbanização da bacia do córrego Lavapés, no município de Rio Claro (SP), utilizaram-se de técnicas cartográficas visando o mapeamento das feições geomorfológicas e do uso da terra nos anos de 1962, 1988 e 2010. Nesse período de avanço da urbanização (Figura 1), as autoras constataram com frequência a redução do número de sulcos erosivos em função da impermeabilização e a reorganização das rupturas topográficas e dos canais pluviais gerados pela construção de aterros e pelo processo de terraplenagem.

Assim, constatou-se que princípios clássicos de linearidade dos processos foram rompidos com o estabelecimento da urbanização. Tradicionalmente, afirma-se que os sulcos erosivos tendem a evoluir para ravinas e, posteriormente, voçorocas, provocando o depauperamento dos solos. No caso ilustrado na Figura 1, a redução dos sulcos pode evitar essa trajetória processual, contudo, deve-se considerar que a fragilidade dos materiais, principalmente dos solos, sobre a qual tais feições se desenvolvem, ainda permanece em subsuperfície; fato que não seria identificado com o uso de outra metodologia, que não avaliasse historicamente o cenário. Ainda, as rupturas topográficas tendem a se estabelecer em função das diferentes resistências dos materiais de subsuperfície, evoluindo para mudanças nas formas das vertentes. Também nessa situação, a identificação das rupturas existentes antes da urbanização, aponta para setores de resistências diferentes dos materiais, o que seria importante de ser considerado quando do estabelecimento do uso urbano. 


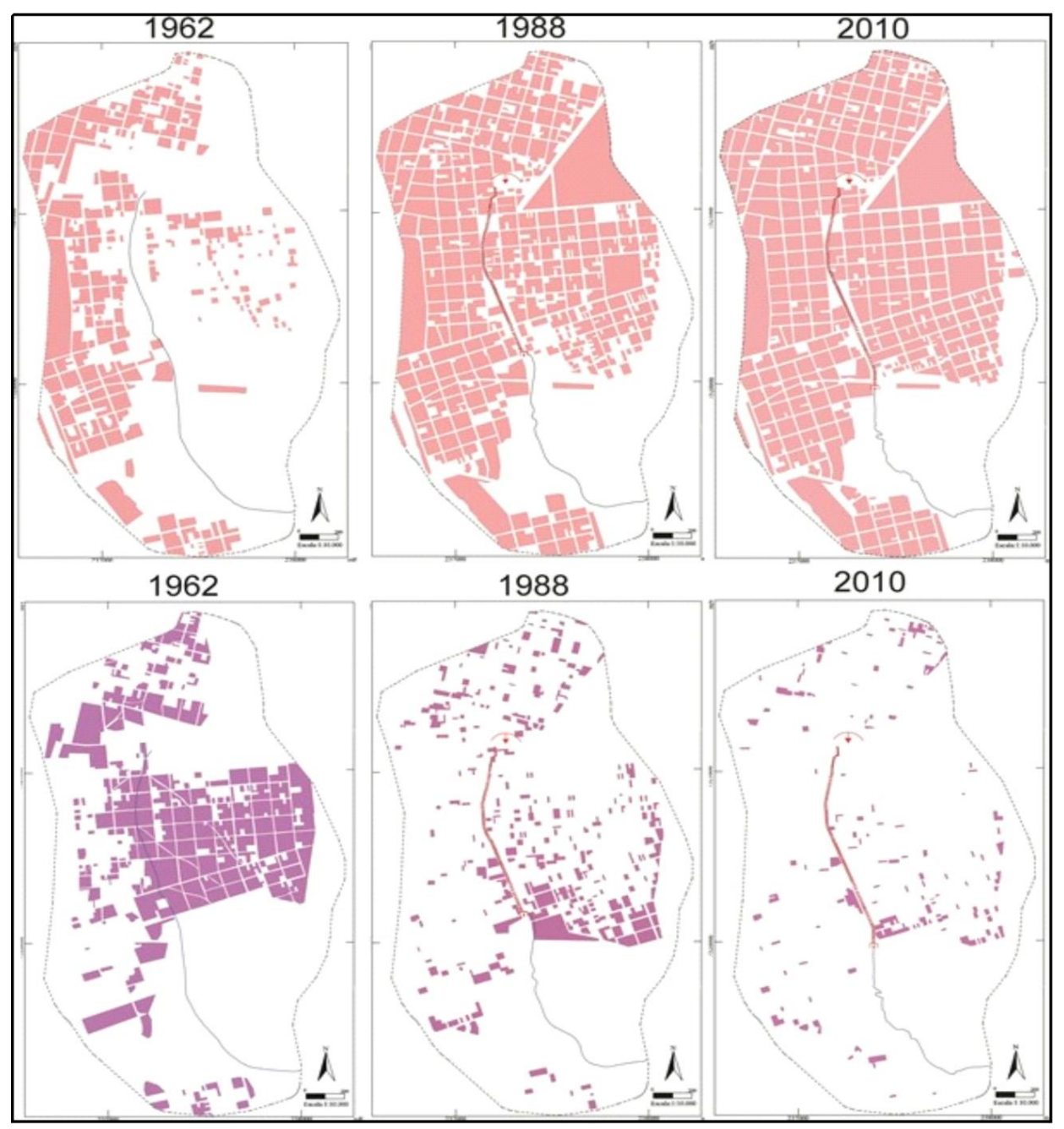

Figura 1. Evolução espacial dos lotes edificados (em rosa) e não edificados (em roxo). Mapas de uso da terra de 1962, 1988 e 2010. Fonte: Fagundes e Lupinacci (2017).

Ao longo do período analisado, as autoras registraram o aterramento da nascente e das áreas de planície e terraço fluvial para construção de avenidas, e a mudança dos canais pluviais, que seguiam a topografia, para as galerias pluviais ao longo de ruas e avenidas. Como consequência, Fagundes e Lupinacci (2017) verificaram a presença de feições geomorfológicas que indicam processo de assoreamento, promovendo o aumento da área de sedimentação na foz do canal Lavapés, em forma de leque. Ainda no médio curso do canal, na margem a $\mathrm{W}$ aterrada, as autoras constataram o desenvolvimento de vegetação característica de área alagada em 1988, com aumento expressivo desta vegetação no ano de 2010, fato que indica mudanças no sistema hidrológico, levando ao afloramento de água em novas situações topográficas (Figura 2).

Os fatos destacados nas Figuras 1 e 2 apontam para uma dinâmica não linear e de incertezas sobre a relação impermeabilização do relevo e afloramentos da água. Tradicionalmente, compreende-se que a evolução da urbanização leva a diminuição da infiltração e, portanto, do afloramento de água em superfície. 


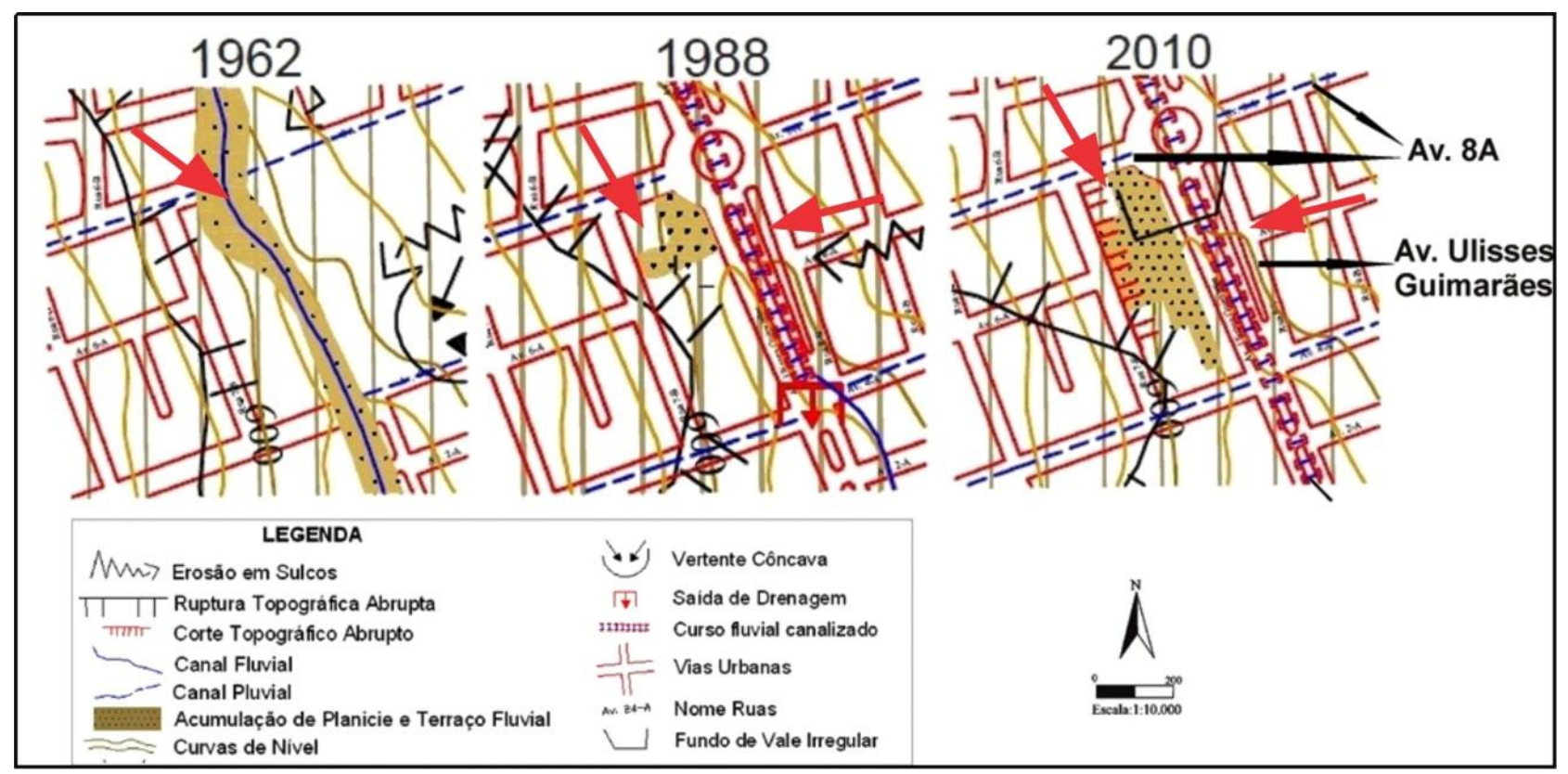

Figura 2. Alterações geomorfológicas observadas no médio curso da bacia hidrográfica do Córrego Lavapés. Fonte: Fagundes e Lupinacci (2017). ${ }^{1}$

Outro trabalho referente ao cenário urbano, foi realizado por Silveira (2013) na cidade de Piracicaba. O referido estudo foi aplicado ao setor periurbano tendo como objetivo construir uma proposta metodológica para a identificação dos níveis de restrição do relevo ao uso urbano, utilizando-se de análises da fragilidade do meio natural e das interferências antrópicas no meio físico durante determinado período histórico.

Deste modo, a partir da formulação de mapeamentos geomorfológicos e de uso e ocupação da terra, Silveira (2013) utilizou-se da cartografia retrospectiva para exemplificar as alterações geomorfológicas produzidas pelo processo de expansão urbana em diversos setores da área analisada (Figura 3).

A partir da análise histórica do setor, Silveira (2013) destacou que em 1962, a monocultura canavieira dominava os interflúvios predominantemente convexizados, ocorrendo uma marcante presença de rupturas topográficas associadas a sulcos erosivos e ravinamentos, sobretudo nas médias e baixas vertentes. No cenário de 1978, o autor registrou uma redução no número de sulcos erosivos e ravinamentos, fato associado à mudança no uso da terra com a expansão da urbanização e das pastagens. Por fim, no último ano (2005), o autor identificou rupturas topográficas e sulcos erosivos que se restringem às bordas urbanas, sendo fato marcante a canalização e alteração do traçado dos cursos fluviais, como pode ser observado na Figura 3. Assim, as mudanças no traçado do canal e, portanto, no nível de base topográfico local podem possibilitar maior potencial erosivo à suas águas, interferindo diretamente na dinâmica de vertentes da referida bacia, de maneira a promover em mudanças em um espaço de tempo histórico, o que dificulta a previsibilidade e consequentemente a incerteza em relação à dinâmica evolutiva da bacia hidrográfica.

\footnotetext{
${ }^{1}$ As setas em vermelho, nessa figura e nas demais, indicam os principais fatos discutidos no texto.
} 


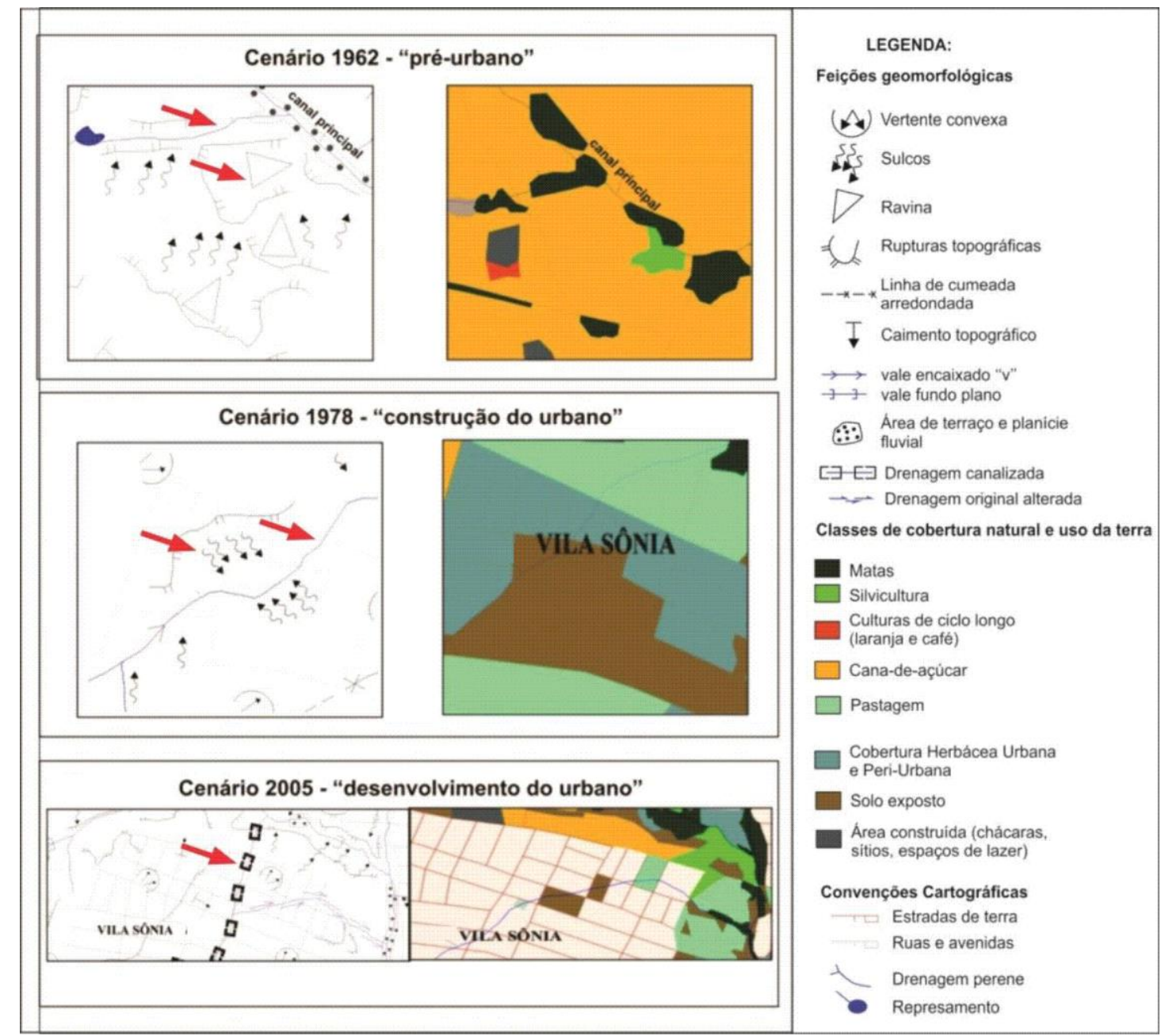

Figura 3. Mapeamentos geomorfológico e de uso da terra nos períodos intitulados pelo autor de "pré-urbanos", "construção do urbano" e "desenvolvimento do urbano". Fonte: Silveira (2013).

Nesse caso, também a presença das feições erosivas e rupturas topográficas apontam para situações de variadas resistências de materiais, demonstrando a importância da análise histórica das feições do relevo. Contudo, o dado mais marcante dessa pesquisa é a atuação do sistema de forçamento vinculado à alteração do canal fluvial. A geomorfologia clássica parte do princípio que, em ambientes quentes e úmidos, o curso fluvial, como nível de base local, comanda as ações denudativas por se constituir no setor mais rebaixado do relevo. Em um cenário com alterações tão bruscas, provocadas pela canalização e realocação da foz de drenagem, as consequências são imprevisíveis para as vertentes e topos adjacentes, cujos processos dependem da ação gravitacional das águas, agora comandadas por outro nível de base e, portanto, por novo padrão de energia. Assim, a alteração do rio provoca mudanças sobre os interflúvios adjacentes impossíveis de serem previstas, criando novas dinâmicas, incertezas e, possivelmente, uma evolução não linear das formas de relevo.

A metodologia de análise histórica também oferece uma compreensão da dinâmica atuante em ambientes rurais, como foi apresentado por Stefanuto e Lupinacci (2017), Zanatta, Cunha e Boin (2015) e Zanatta, Lupinacci e Boin (2017). 
Stefanuto e Lupinacci (2017) estudaram os terrenos que se caracterizam pelo contato entre a Depressão Periférica Paulista e as Cuestas Basálticas, que dão origem a Serra do Cuscuzeiro localizada em Analândia (SP). A área constitui-se ainda, de acordo com Pinton (2011), em um setor de franca expansão agrícola, com a consolidação, a partir de 1988, de áreas de pastagem e cana-de-açúcar.

Assim, o estudo desenvolvido pelos autores apresenta uma análise histórica a partir de dados dos anos de 1962, 1988 e 2010, detalhando dois recortes espaciais do setor cuestiforme de Analândia (SP) nos quais uma feição linear do tipo voçoroca e algumas drenagens apresentaram respostas não lineares mediante a atuação de sistemas de forçamento. Salienta-se que para obtenção de dados da área, os autores formularam mapeamentos geomorfológicos e de uso e ocupação da terra dos três anos analisados, em escala de 1:50.000.

No primeiro setor (Figura 4), no qual foi mapeada uma feição erosiva do tipo voçoroca, Stefanuto e Lupinacci (2017) identificaram, durante o período 1962 a 1988, a manutenção da referida feição, acompanhada pelo aumento de 11,6\% na classe de uso da terra vegetação arbórea. Já no período de 1988 a 2010, os autores verificaram um novo aumento na referida classe de uso, de mesma monta, além do barramento do curso fluvial mapeado no interior da forma erosiva. Assim, de acordo com Stefanuto e Lupinacci (2017), a ampliação das áreas com vegetação arbórea, como também o barramento do curso fluvial, permitiram que a voçoroca em questão apresentasse uma estagnação de seu talude erosivo, conjuntamente com uma recuperação parcial da área evidenciada em 2010 (Figura 4).

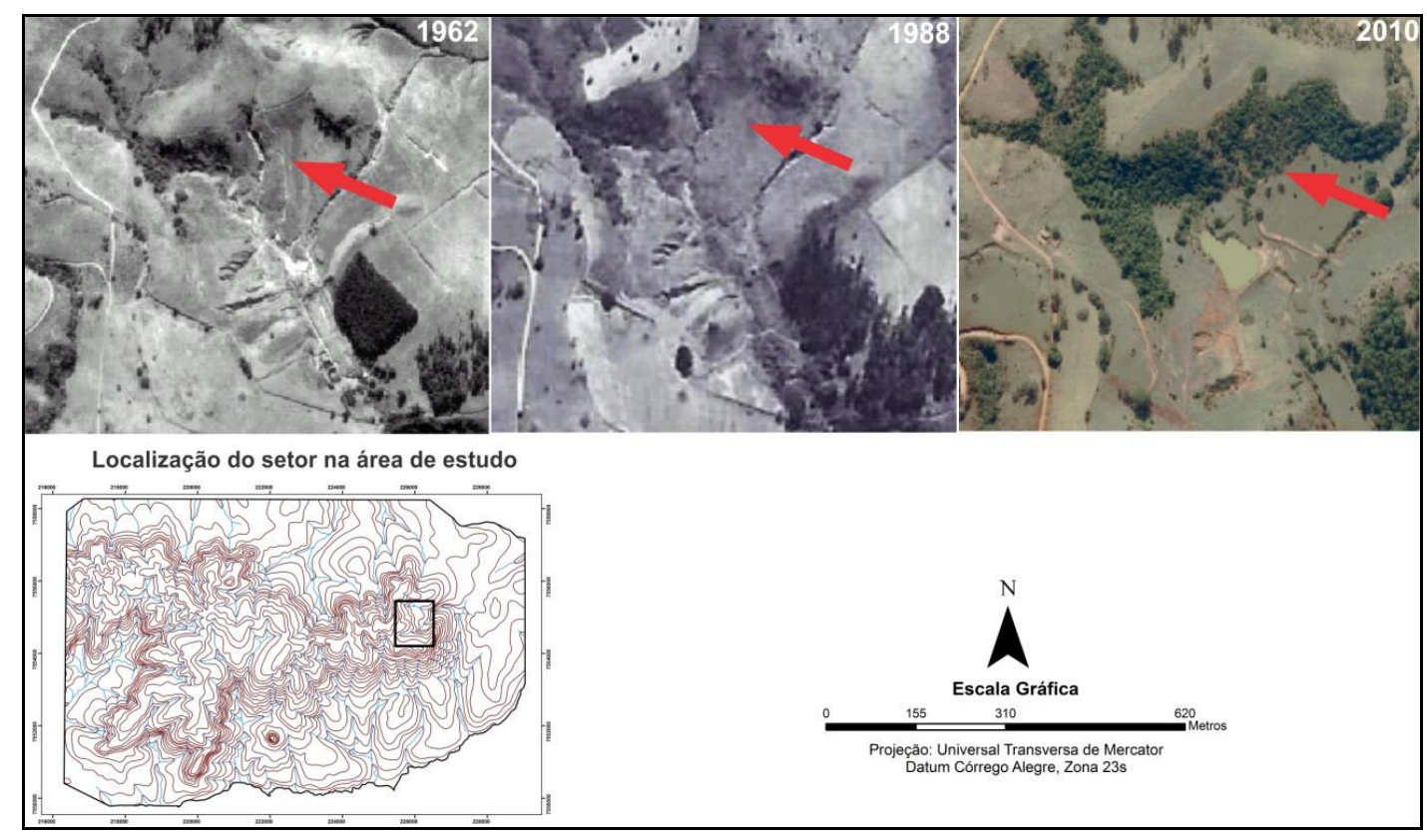

Figura 4. Análise comparativa da área de ocorrência de voçoroca em Analândia, em diversos anos distintos. Fonte: Stefanuro e Lupinacci (2017).

Já no segundo setor (Figura 5), Stefanuto e Lupinacci (2017) identificaram que, na transição entre os anos de 1962 para 1988, ocorreu uma expressiva diminuição dos canais fluviais. No período seguinte, entre 1988 e 2010, alguns córregos ressurgem, mas a área não chega a recupe- 
rar todos os canais fluviais existentes em 1962. Assim, durante a análise histórica do uso da terra ficou registrado que a classe vegetação arbórea apresenta crescimento expressivo, uma vez que em 1962 ocupava uma área de 13\% do setor e em 1988 passa a ocupar 36,8\%, reduzindo para $24 \%$ em 2010, fato não acompanhado pelo aumento da densidade de drenagem no setor em 1988. Os autores constataram ainda um aumento de 5,53 vezes nas lavouras temporárias de $1962(1,5 \%)$ para 1988 (8,3\%), ressaltando que os setores de ocorrência dessa cobertura superficial no ano de 1988 se desenvolveram sobre as áreas de nascentes identificadas em 1962.

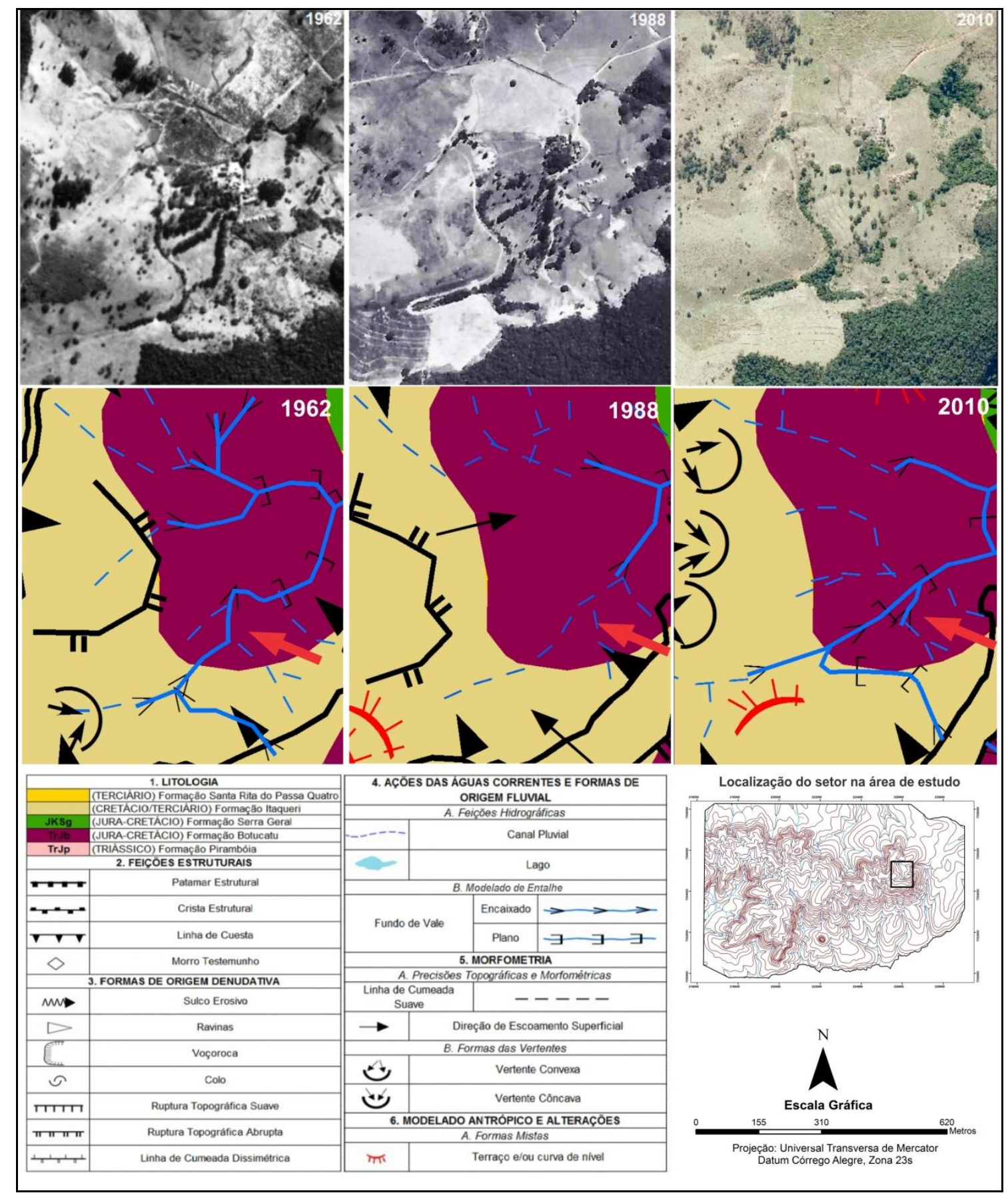

Figura 5. Alteração no sistema fluvial em setor de Cuestas em Analândia (SP). Fonte: Stefanuto e Lupinacci (2017). 
Assim, foi possível verificar que a partir da atuação de sistemas de forçamento de origem antrópica, representados pelo barramento no curso fluvial e pela implantação de setores de cultivo agrícola, os sistemas analisados exibiram comportamentos bastante diferenciados. No caso da voçoroca, as medidas desencadeadas pela ação humana possibilitaram a estagnação do talude erosivo, demonstrando que as ações anteriores não ultrapassaram o limiar do sistema. Já no segundo setor, a resposta à ação humana foi diferenciada, demonstrando que, mesmo com o aumento de áreas de mata, o sistema fluvial ainda permanece afetado, com um número menor de nascentes do que o registrado no primeiro ano mapeado (1962), contudo apresentando uma oscilação no ano intermediário (1988), marcando um comportamento não linear bastante expressivo. Esses fatos demonstram a complexidade e a dificuldade de previsibilidade do comportamento dos sistemas físicos frente às diferenciadas ações humanas.

Os trabalhos de Zanatta, Cunha e Boin (2015) e Zanatta, Lupinacci e Boin (2017) são outros exemplos de aplicação da análise histórica em ambientes rurais, destacando-se dois estudos desenvolvidos no município de Marabá Paulista, extremo Oeste do estado de São Paulo, no compartimento geomorfológico do Planalto Ocidental Paulista. No primeiro, em escala 1:50.000, os autores analisaram a alta bacia do ribeirão Areia Dourada, mapeando as feições geomorfológica e de uso da terra de 1962 e 2012; enquanto no segundo (ZANATTA; LUPINACCI; BOIN, 2017), os autores selecionaram uma subbacia do ribeirão Areia Dourada com voçorocamento, avaliando a problemática através de mapeamentos geomorfológicos e de uso da terra de 1963, 1979, 1997, 2010 e 2015, em escala 1:10.000.

$\mathrm{Na}$ alta bacia do ribeirão Areia Dourada, Zanatta, Cunha e Boin (2015) levantaram que no período analisado, desde 1962, poucas áreas encontravam-se recobertas por vegetação florestal do tipo estacional semidecidual, que compreenderam menos de $1 \%$ do total da área estudada, resultando, de 1962 para 2012, no aumento de 130 para 385 feições em sulco, de seis para 138 ravinamentos e de zero para sete processos de voçorocamento. Nesse período, de acordo com Rodrigues et al. (2006), a partir da década de 1970, com o avanço de grandes pecuaristas na região, no intuito de conter os processos erosivos atuantes, foram construídos terraços agrícolas nas áreas de pastagem. No entanto, tais terraços contribuíram para a reativação dos afloramentos de água, característicos de terrenos sobre a Formação Adamantina, que intercala bancos arenosos sobre argilosos, resultando em extensas áreas de afloramento em vários setores de vertentes. Tais afloramentos deram origem a diversos filetes de água perenes que escoam para jusante em terrenos recobertas por pastagens, condições que contribuíram para o aumento das feições erosivas mapeadas (Figura 6). 


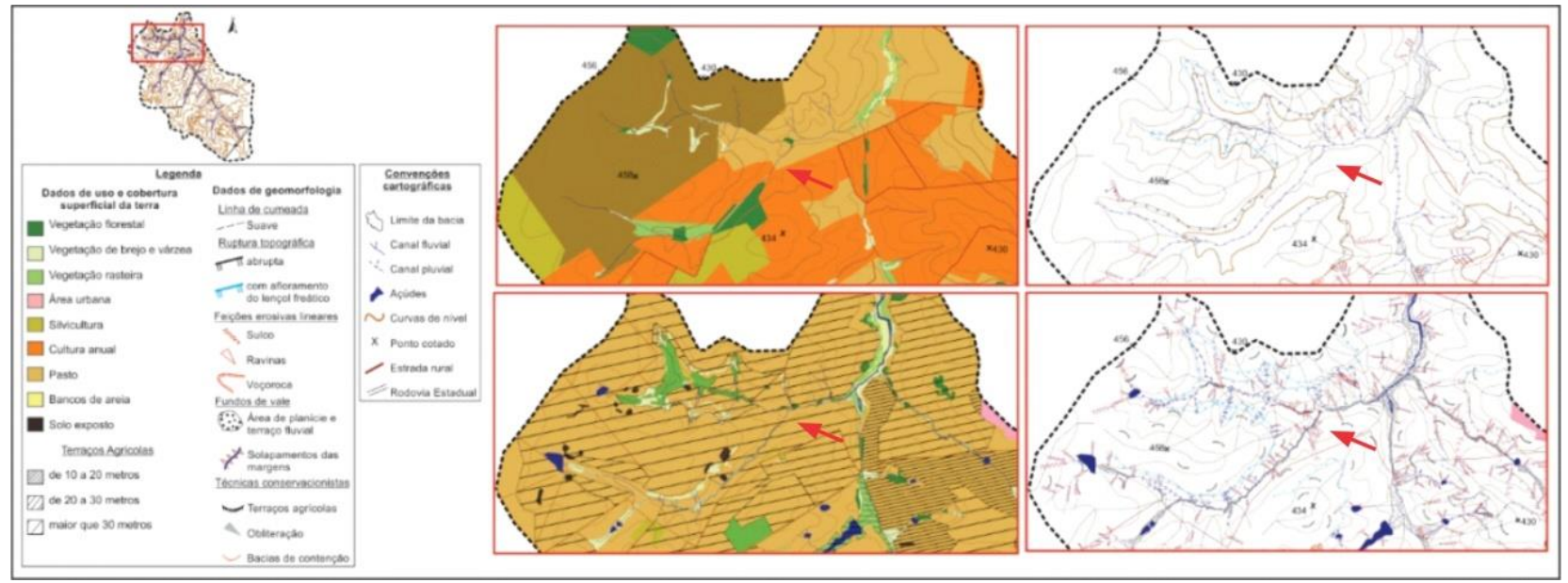

Figura 6. Mudanças no uso e cobertura superficial da terra e das feições geomorfológicas do ano de 1962 para 2013 do setor NW da alta bacia do ribeirão Areia Dourada, Marabá Paulista (SP). Fonte: Zanatta, Cunha e Boin (2015, p.15).

Zanatta, Lupinacci e Boin (2017), em análise de uma subbacia do ribeirão Areia Dourada, atingida por extenso processo de voçorocamento, identificaram que o barramento do canal voçorocado, junto dos terraços agrícolas nas vertentes com uso para pastagem, alteraram a dinâmica dos processos erosivos. Assim, no período de 1963 a 1997, as ravinas foram mapeadas apenas em concavidades, com cabeceira da média para alta vertente, a partir do barramento do canal em 2010, essas feições passam a se desenvolver também a partir das baixas vertentes convexas e retilíneas (Figura 7).

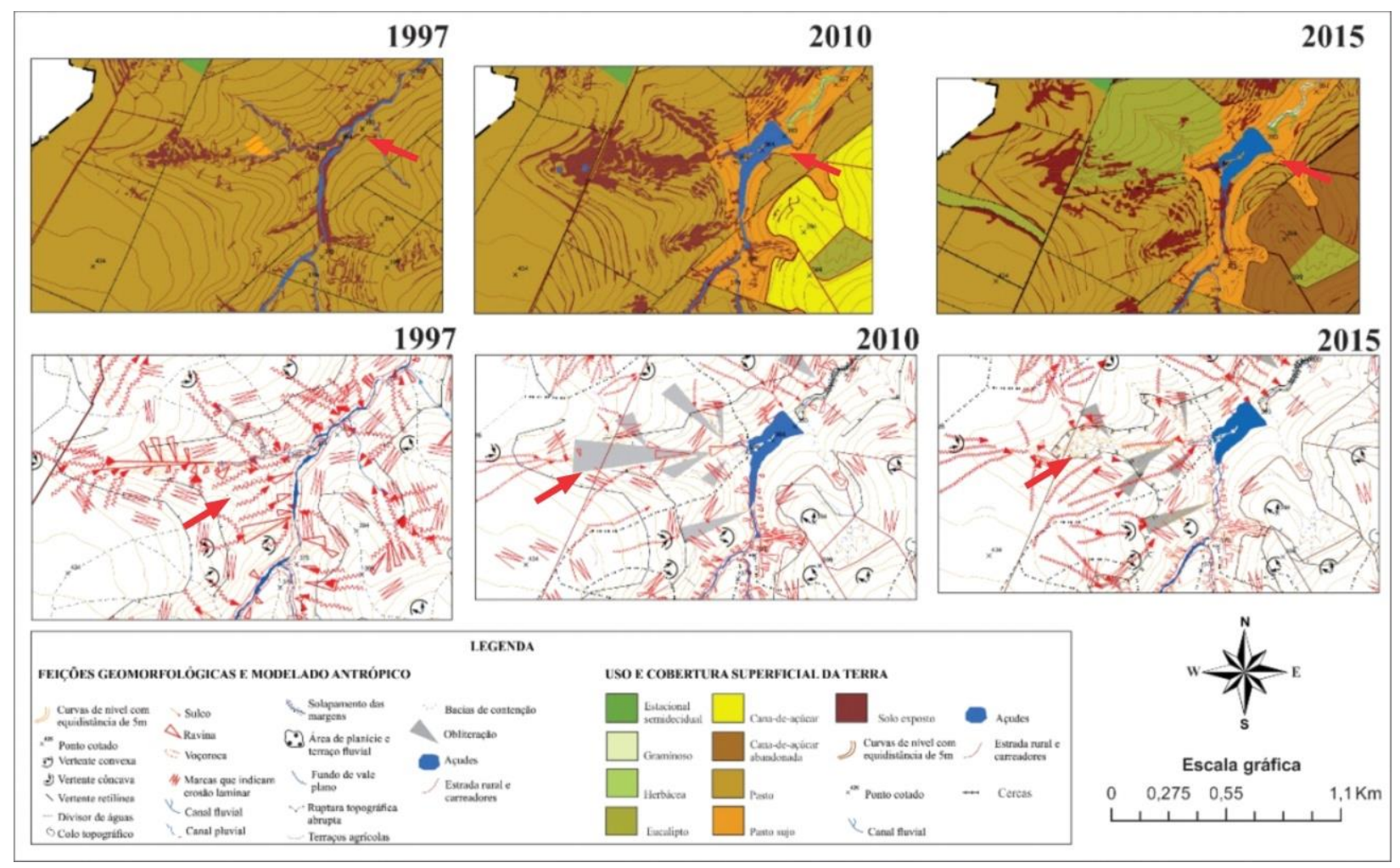

Figura 7. Uso e cobertura superficial da terra, feições geomorfológicas e modelado antrópico na média bacia nos cenários de 1997, 2010 e 2015. Fonte: Zanatta, Lupinacci e Boin (2017, p. 2655). 
Nesse artigo, os autores utilizaram do Coeficiente de Correlação de Pearson para validar as situações levantadas através da análise cartográfica retrospectiva, mediante quantificação das variáveis de uso e cobertura superficial da terra e das feições geomorfológicas dos mapeamentos nos cinco cenários (1963, 1979, 1997, 2010 e 2015). Nas correlações, todas as formas erosivas mapeadas (marcas que indicam erosão laminar, sulco, ravina e voçoroca) apresentaram correlação positiva de moderada à perfeita com todas as técnicas conservacionistas e de contenção dos processos erosivos (terraços agrícolas, obliteração e bacias de contenção), o que indica uma relação direta entre essas duas classes temáticas.

Em ambas as análises, os autores consideraram que o uso da cartografia geomorfológica retrospectiva traz importantes contribuições para o entendimento da dinâmica erosiva nas áreas agrícolas, nas quais constataram dinâmicas não lineares e incertezas a respeito do efeito do uso de práticas conservacionistas tradicionais e de contenção de processos erosivos em ambientes rurais degradados. Para os autores, as distintas intervenções antrópicas levantadas, sobrepostas as Formações areníticas do Grupo Bauru, como a Adamantina e as suas características hidrodinâmicas, proporcionam modificações inesperadas. Ainda, as técnicas conservacionistas se correlacionam de forma inquestionável, segundo os autores, com o aumento dos afloramentos de água nas vertentes, assim como o barramento nos canais com voçorocamento, alteram a dinâmica e localização dos ravinamentos. Nesses ambientes relatados por Zanatta, Cunha e Boin (2015) e Zanatta, Lupinacci e Boin (2017), os sistemas de forçamento de caráter antrópico, mesmo quando buscaram reparar os fenômenos erosivos, não apresentam resultados eficientes, gerando maior incerteza e comportamento espacial pouco previsível das feições erosivas.

\section{Considerações finais}

Os estudos de caso mencionados demonstraram alterações das formas de relevo em ambientes diversificados e em situações de uso da terra também bastante distintas. Dessa forma, buscou-se demonstrar como o uso da terra interfere de forma sistemática na dinâmica do relevo, provocando em algumas situações a dinamização dos processos naturais (STEFANUTO; LUPINACCI, 2017) e em outras mudanças morfológicas intensas que levam aos autores (FAGUNDES; LUPINACCI, 2017) a defenderem a geração de uma morfologia antropogênica.

Assim, o uso da terra compreendido como um sistema de forçamento pode levar os sistemas geomorfológicos a ultrapassarem seus limiares de recuperação, assim como podem tornar os ambientes bastante complexos ao sobreporem historicamente ações que determinam morfodinâmica não linear. Os dados de Fagundes e Lupinacci (2017) sobre a diminuição dos sulcos erosivos e de Stefanuto e Lupinacci (2017) sobre a estagnação de talude em voçoroca, são exemplos em que o sistema de forçamento derivado da ação antrópica produz resultados aparentemente positivos. Contudo, deve-se considerar que essas ações são realizadas sobre um terreno já anteriormente alterado, cuja dinâmica natural já não se registrava. Ainda, sobre tais sistemas de forçamento é importante notar que as informações trazidas por Zanatta, Lupinacci e Boin (2017) mostram que a intencionalidade de tais sistemas nem sempre é eficiente. Assim, no exemplo citado, a presença de técnicas conservacionistas tem correlação matemática evidente com o aumento de feições erosivas, resultando em um ambiente bastante complexo e pouco previsível. 
Dessa forma, os dados históricos de uso da terra são essenciais para a compreensão das formas de relevo que existem no presente. Tais formas constituem-se em sistemas complexos nos quais interagem os elementos naturais com as ações humanas historicamente constituídas, abarcando uma dinâmica não linear. Tal dinâmica, portanto, apresenta certo grau de incerteza. Agrega-se ainda a essa questão, a disponibilidade de poucos dados sobre o funcionamento geológico da Terra, criando dificuldades em se estabelecer os limiares entre fenômenos de caráter natural e aqueles produzidos pela ação humana em tempo histórico.

Avalia-se assim que os dados históricos permitem levantar hipóteses sobre a possível dinâmica dos terrenos, possibilitando diminuir o grau de incerteza e, no futuro, construir modelos que viabilizem estabelecer uso da terra mais adequado às condições físicas e históricas locais.

Agradecimentos

À Fundação de Amparo à Pesquisa do Estado de São Paulo - FAPESP, pelos financiamentos. Processos no 2016/25399-1 e $n^{\circ}$ 2015/00875-2

Submetido em 30 de novembro de 2017. Aceito para publicação em 15 de março de 2018. 
Referências

BROWN, E. H. O homem modela a Terra. Boletim Geográfico v. 30, n. 222, p. 01-18, 1971.

CARVALHO, M. B. Geografia e complexidade. Scripta Nova. (Revista Eletrônica de Geografia y Ciências Sociales). Barcelona, n. 34, 1999.

CHAUI, M. Convite à filosofia. São Paulo: Ática, 1994.

CHOLLEY, A. Observações sobre alguns pontos de vista geográficos. Boletim Geográfico v.22, n.179, 1964.

CHORLEY, R. J. A geomorfologia e a teoria dos sistemas gerais. Notícia Geomorfológica. Campinas, v.11, n.21, p. 3-22, 1971.

CHORLEY, R. J.; KENNEDY, B. A. Physical Geography: a systems approach. London: Prentice Hall, 1971.

CHRISTOFOLETTI, A. Epistemologia da geomorfologia: resenha. Notícia Geomorfológica. Campinas, v.11, n.22, p.73-75, 1971.

CHRISTOFOLETTI, A. Análise de Sistemas em Geografia - Introdução. São Paulo: HUCITEC, 1979.

CHRISTOFOLETTI, A. Modelagem de sistemas ambientais. São Paulo: Edgard Blücher, 1999.

FAGUNDES, A.; LUPINACCI, C. M. Urbanização e Alterações geomorfológicas: O Caso da Bacia Hidrográfica do Córrego Lavapés: Rio Claro (SP). Revista do Departamento de Geografia, v.33, p.47-62, 2017.

GOUDIE, A. The human impact on the natural environment. Cambridge: MIT Press, 1986.

GUERRA, A. T. A Geografia aplicada na conservação dos recursos naturais básicos, tendo em vista o poder nacional e a segurança nacional. Revista Brasileira de Geografia v.28, n.1, p. 57-60, 1966.

HAFF, P. K. Newgeomorphology, prediction and the anthoropic landscape. Duke University, Durham, 2008.

HOBSBAWM, E. J. A Era das Revoluções: Europa 1789-1848. Rio de Janeiro: Paz e Terra, 1981.

HOWARD, A. D. Equilíbrio e Dinâmica dos Sistemas Geomorfológicos. Notícia Geomorfológica. n.13, v.26, p.3-20, 1973.

MORIN E. Introdução ao pensamento complexo. Porto Alegre: Sulina, 2006.

MURRAY, A. B.; LAZARUS, E.; ASHTON, A.; BAAS, A.; COCO, G.; COULTHARD, T.; FONSTAD, M.; HAFF, P.; MACNAMARA, D.; PAOLA, C.; PELLETIER, J.; REINHARDT, L. Geomorphology, complexity, and the emerging science of the Earth's Surface. Geomophology. v.103, p. 496-505, 2009.

NIR, D. Man, a geomorphological agent: an introduction to anthropic geomorphology. Jerusalem: Katem Pub, House, 1983. 
PELOGGIA, A. O Homem e o Ambiente Geológico: Geologia, Sociedade e Ocupação Urbana no Município de São Paulo. São Paulo: Xamã, 1998.

PHILLIPS, J. C Nonlinear dynamical systems in geomorphology: revolution or evolution? Geomorphology, v.5, p.219-229, 1992.

PINTON, L. de G. A Antropogeomorfologia na bacia do Córrego do Cavalheiro - Analândia/SP: Uma avaliação da dinâmica de uso da terra e sua adequabilidade a legislação ambiental e a capacidade de uso. 2011. 102 f. Trabalho de Conclusão de Curso - Instituto de Geociência e Ciências Exatas, Universidade Estadual Paulista, Rio Claro, 2011.

RECLUS, É. A complexidade da produção do espaço geográfico. In: ANDRADE, M. C. de (org.). Élisée Reclus. São Paulo: Ed. Ática, 1985, p. 56-60.

RODRIGUeS, J. O. N.; PERUSI, M. C.; PETERLINI, G. H. C.; TIEZZI, R. O.; PISANI, R. J.; SANTANA, E. L. R. Variações texturais dos Latossolos Vermelhos do assentamento rural Antonio Conselheiro - Mirante do Paranapanema (SP). Geografia em Atos v.1, n.6, p. 3039, 2006.

RODRIGUES, C. A Urbanização da metrópole sob a perspectiva da geomorfologia: tributo de leituras geográficas. In: CARLOS, A. F. A.; OLIVEIRA, A. U. de. (Org.). Geografias de São Paulo: $1^{\mathrm{a}}$ Representação e crise da Metrópole. São Paulo: Contexto, 2010. p. 89-113.

SILVERIA, A. Proposta metodológica para avaliação dos níveis de restrição do relevo ao uso urbano. Tese (Doutorado). Rio Claro: Programa de Pós-Graduação em Geografia, Universidade Estadual Paulista, 2013.

STEFANUTO, E. B.; LUPINACCI, C. M. Atuação dos sistemas de forçamento nos sistemas terrestres a partir da ação antrópica. In: XVII Simpósio Nacional de Geografia Física Aplicada e I Congresso Nacional de Geografia. 2017, Campinas. Anais... Campinas, 2017. p. 61516161.

SUERTEGARAY, D. M. A.; NUNES J. O. R. A Natureza da Geografia Física na Geografia. Terra Livre n.17, p.11-24, 2001.

TRICART, J. La Geomorphologie et les hommes. Rev. Geom. Dynamique. v. 4, p. 154- 156, 1956.

VICENTE, L.E.; PEREZ FILHO, A. Abordagem sistêmica e Geografia. Geografia. Rio Claro, v. 28, n. 3, p. 345-362, 2003.

ZALASIEWICZ, J; WATERS, C.N.; SUL, J.A.I.; COCORAN, P.L.; BARNOSKY, A.D.; CEARRETA, A.; EDGEWORTH, M.; GALUSZKA, A.; HEABDEKM C.; LEINFELDER, R.; MCNEIL, J.R.; STEFFEN, W.; SUMMERHAYES, C.; WAGREICH, M.; WILLIAMS, N. WOLFE, A.P.; YONAN, Y. The geological cycle of plastics and their use as a stratigraphic indicator of the Anthropocene. Anthropocene. n. 13, p.4-17, 2016.

ZANATTA, F. A. S; CUNHA, C. M. L.; BOIN, M. N. O uso da terra e alterações do relevo na alta bacia do ribeirão Areia Dourada, Marabá Paulista (SP). Revista Brasileira de Geomorfologia v.16, n.1, p. 03-17, 2015. 
ZANATTA, F. A. S.; LUPINACCI, C. M.; BOIN, M. N. Interferência antrópica e dinâmica erosiva: estudo de caso em área rural degradada no Oeste Paulista. In: Encontro Nacional da Associação Nacional de Pós-Graduação e Pesquisa em Geografia (ENANPEGE). 12. 2017, Porto Alegre (RS). Anais... Porto Alegre, 2017. p. 2651-2662. 